\title{
DIE COMMISSION OF THE CHURCHES ON INTERNATIONAL AFFAIRS.
}

\section{DS. C. J. VILJOEN}

Hierdie liggaam is in 1946 gestig tydens 'n konferensie van kerkleiers oor internasionale aangeleenthede te Cambridge, en is oorspronklik gekonstitueer deur die Wêreldraad van Kerke (W.R.) en die International Missionary Council. Die doelstellinge het tot die huidige toe dieselfde gebly $\mathrm{nl}$. om die wil van God te stel t.o.v. die menigte probleme van die wêreldpolitiek en ekonomie, met juiste informasie en wyse geestelike insig. Dit bly die taak van die Kerk om 'n Christelike sienswyse aan die verantwoordelike mense te gee en hulle aan die Christelike opdragte te herinner.

In hierdie optrede neem die Kommissie hom in ag om nie aanleiding tot wedersydse wantroue te gee nie.

Die 1964-65 jaarverslag meld dat die groeiende begrip van die Kerke in hulle positiewe taak in internasionale aangeleenthede vir die Kommissie 'n groot hulp was in hierdie moeilike tyd. Dit is duidelik dat hulle slegs sukses kan behaal as hulle op die aktiewe ondersteuning van kerklike liggame op die internasionale vlak kan reken.

\section{HULLE DOELSTELLINGS :}

Die algemene verantwoordelikheid is om die ledekerke en rade van die W.R. van raad te bedien (asook aan te spoor) in hulle benadering tot internasionale probleme. Hulle moet bydra "to formulate the Christian mind on world issues". Om dit te kan doen moet hulle :

1. Rade en Kerke wys op probleme wat op die Christelike gewete beslag lê, en optrede aanbeveel waarmee Christene effektief in die verband kan handel.

2. Christelike beginsels ontdek en formuleer wat betrekking het op die verkeer tussen volkere.

3. Die middele vind waardeur die Christelike gewete wakker gemaak kan word en opgevoed kan word t.o.v. hulle verantwoordelikheid in hierdie wêreld van nasies.

4. Materiaal versamel en beskikbaar stel i.v.m. die verhouding van kerke tot openbare sake. 
5. 'n Studie maak van die internasionale reg, asmede ekonomiese en sosiale vraagstukke en dit beskikbaar stel.

6. Die werk verdeel onder toegeruste komitees.

7. Konferensies organiseer vir kerkleiers van verskillende nasies.

8. Die W.R. verteenwoordig voor internasionale liggame soos die V.V.O. en hierdie liggame help in :

(a) Die ontwikkeling en kodifisering van internasionale reg en ontwikkeling van bowenasionale instellings; en leiding

(b) om menslike regte te respekteer; veral i.v.m. godsdiensvryheid;

(c) om internasionale bewapening te reguleer;

(d) internasionale ekonomiese samewerking te bevorder;

(e) alle volke sover te kry om die algehelee welsyn van afhanklike volke te bevorder.

9. Van tyd tot tyd samesprekings met ander organisasies hou wat soortgelyke doelstellings het.

Hulle werk dan ook nou saam met die W.R. en sy 218 ledekerke in 90 lande. Aanbevelings van die C.C.I.A. dien voor die uitvoerende liggame van die W.R., en lg. se verklarings moet dan weer die werk van die Kommissie rig.

Onder die kontakte van die Kommissie tel groepe in Afrika (All-Africa Conference of Churches se Kommissie), Oos-Asië, Australië, Denemarke, Finland, Frankryk, Duitsland, Griekeland, Hongarye, Indië, Indonesië, Japan, Korea, Nederland, Nu-Zeeland, Noorweë, Pakistan, Fillipyne, Suid-Afrika (Christian Council of S.A.), Swede, Switserland, Engeland, V.S.A. en Rusland.

\section{DIE JONGSTE RAPPORTE 1966 - 67.}

1. All-Africa Conference of Churches. Hulle was hoofsaaklik besig met die oproere in die Soedan en het hulle beywer vir die terugkeer van duisende vlugtelinge daarheen.

2. Kanada. Daar het hierdie komitee sy jaarlikse seminaar oor internasionale aangeleenthede gehou en eminente sprekers soos die premier Pearson, Kenneth Bailey, R. Bilheimer en Dr. Ngcobo van Rhodesië laat optree. China, Rhodesië, S.A., Vietnam en Indië was in die verdere besprekings ingesluit asook voedsel- en bevolkingsprobleme.

3. Duitsland. Die Duitse Nasionale komitee van die C.C.I.A. het op godsdiensvryheid en Vietnam gekonsentreeer in sy werk. Voor. 
studie vir die 4de vergadering van die W.R. te Uppsala 1968 is gedoen oor: Die Teologie van die Rewolusie.

4. Korea het geantwoord op wat deur die C.C.I.A. gesê is oor Vietnam, en hulle verslag lewer heelwat kritiek, in 'n poging om samewerking te verkry. So kritiseer hulle ' $n$ advies om China op die V.V.O. sitting te laat kry, as "influenced by political pragmatism, ... . applying the 'Principal of Compromise'." So ook wys hulle die Bangkok konferensie af as synde vol vooroordeel, en vra waarom die bywoning van leiers uit lande soos Korea, Nasionalistiese China en Suid-Vietnam geweier is op die konferensies. Die gevolg was veel vooroordeel en onregverdigheid, alles behalwe die regte soort naasteliefde. Dan kom ' $n$ veelseggende sin voor: "We are no longer living in an age in which an individual or a minority can dominate world opinion".

5. Swede spreek hulle deur die Sweedse Ekumeniese Komitee oor Internasionale Sake sterk uit oor die beëindiging van die oor$\log$ in Vietnam.

6. In Engeland het die Britse Raad vir Kerke hulle met ' $n$ verskeidenheid sake op internasionale vlak besig gehou. Wêreldarmoede was onder die soeklig met 'n publikasie World Poverty and British Responsibility. Die Roomse Kerk in Engeland het hierin saamgewerk. Rhodesië bly belangrik en hulle beklemtoon Engeland se plig om geregtigheid te herstel en ' $n$ aanvaarbare meerderheidsregering daar te stel. "Rhodesia and Ourselves" is " $n$ pamflet wat sensasionele onthullings doen oor rassisme in Rhodesië. Oor Vietnam word hoofsaaklik op vrede aangedring en ' $n$ beroep op die V.S.A. gedoen om ' $n$ meer oortuigende demonstrasie te lewer van hulle voorneme om vrede te maak. Voorts hou die Raad hulle besig met ontwapening en die ooreenkoms om geen kernwapens wat die wêreld met hul uitval besoedel, meer af te vuur nie.

Dan is daar ' $n$ tweegesprek begin tussen Christene en Marxiste wat so sê hulle, gebore is uit die begeerte van beide om hulle posisies weer te ondersoek in die lig van kritieke toestande in die hoop dat hulle weë mag vind om saam te werk tot die vrede en welvaart van die mensdom. Dan word gemeld dat die Kommuniste in Engeland hulle kolomme in hul blad "Marxism Today" oopgestel het vir Christene om hulle oogmerke te stel.

7. Rusland. Die Russiese Ortodokse Kerk neem aan Internasionale aangeleenthede deel deur hul "Foreign Relations Dept.," wat verbonde is aan die Sinode van die Kerk: en hulle werk deur die Raad van Godsdienstige Sake van die Russiese ministeriële Raad 
as hulle kontak met ander groepe wil maak. Die werk word geredigeer deur Patriarg Alexei en die Sinode.

Daar is tekens dat hulle geleerdes besig is met die probleme van Christelike verantwoordelikheid in internasionale sake in verband met sowel teologiese as sekulêre aktiwiteit.

Hulle het 'n aandeel geneem in die Kerk en Gemeenskap vergadering 1966 en die "Christian Peace Conference" (veral met die oog op Vietnam). Die militêre oorname in Griekeland het ook 'n telegram van Alexei na Koning Konstantyn ten gevolge gehad waarin hy vra dat die demokratiese beginsel aan die volk toegeken sal word.

Hulle het voorts 'n studie gemaak van die kontemporêre Christelike denke, veral in sy sosiale aspekte. Dis sosiale houding van die R.K.K. is behandel by die Wêreldkonferensie van „Kerk en Gemeenskap" deur metropoliet Nikodim.

\section{VERDERE KONTAKTE VAN DIE C.C.I.A.}

Hierdie Kommissie tree voorts op as verteenwoordiger van Christelike Kerke en liggame by internasionale liggame soos die V.V.O. en sy rade. So het die C.C.I.A. formele verhoudings met die Voedsel en Boerdery Organisasie, Unesco, V. V. Kinderfonds, en die Internasionale Arbeidsorganisasie, die afdeling van Tussenkerklike hulp, Vlugteling organisasies ens.

\section{BELANGRIKSTE TAKE VAN HIERDIE LIGGAAM.}

A .Internasionale vrede en veiligheid.

Op hierdie terrein is die reeds gemelde Vietnam-oorlog die belangrikste, maar hulle verswyg ook nie die onopgeloste probleme in Suider Afrika, Kasjmir en Ciprus en die Israeli-Arabiere kwessie nie.

Dan meld hulle die pogings tot ooreenkomste tot ontwapening en die staking van die kernwedloop. Hulle beywer hulle dan ook vir die vredevolle gebruike van atoom-energie asook die vredevolle gebruike van die buitenste ruim.

\section{B. Menseregte en Godsdiensvryheid.}

Om op hierdie twee ag te gee, is heel besonderlik die taak van die C.C.I.A. Hulle het in hierdie opsig 'n tweërlei doelstelling :

1. Die ontwikkeling van internasionale standaarde en veiligheidsmaatreëls om basiese menseregte te verdedig. 
2. Om huishoudelike konstitusies en wette en administratiewe praktyke in ooreenstemming met aanvaarde internasionale standaarde te bring.

Wat hierdie internasionale standaarde is, bepaal die C.C.I.A. van tyd tot tyd; veral t.o.v. rassediskriminasie, godsdienstige onverdraagsaamheid, die reg van toevlug en die vryheid om informasie te verskaf. Hierdie standaarde hang dan ook ten nouste saam met die aktiwiteite van die V.V.O. Laasgenoemde liggaam het die volgende aanvaar, wat toegejuig is deur die C.C.I.A.

(i) Die internasionale ooreenkoms oor internasionale politieke en siviele regte,

(ii) Die internasionale ooreenkoms oor ekonomiese, sosiale en kulturele regte,

(iii) 'n Opsionele protokol i.v.m. (i).

Dan sien ook 'n konsep-ooreenkoms ter uitskakeling van alle vorms van godsdienstige onverdraagsaamheid die lig.

Aan liggame in Spanje is in verband hiermee voorligting gegee, en ten spyte van wetgewing wat ingedien is, was daar soveel amendemente dat slegs gerapporteer kan word dat in Spanje min vooruitgang gemaak is; ten spyte van 'n toegeeflike houding in die Deklarasie oor Godsdiensvryheid deur die Tweede Vatikaanse Konsilie. Dit skyn of die meeste probleme in Moslemlande voorkom of waar 'n nie-Christelike of die Roomse godsdiens oorheersend is.

Wanneer rasse-aangeleenthede ter sprake kom, is S.A. in die prentjie. Die verslag verwys na die sluipmoord op $\mathrm{dr}$. Verwoerd wat "from the scene the leading apologist of a particular theory of race relations" verwyder het; "and his successor's style of policy has revealed a marginal flexibility the significance of which has still to be assessed".

S.W.A., Rhodesië, Zambië, Mosambiek, Soedan, Nigerië en V.S.A. bly bronne van bekommernis.

\section{Die Bevordering en Vooruitgang van afhanklike volke.}

Hierdie saak is een van die belangrike doelstellings van ons Kommissie, wat hulle op tussenregerings-vlak wil doen. Dit groei uit die ekumeniese beoordeling van die gevare van kolonisasie en die doelstelling bly om alle nasies daartoe te bring om politieke onafhanklikheid te verleen aan afhanklike volke en om soveel moontlik te doen om hulle welvaart te bevorder. 
Hulle verklaar dat Christelike besorgdheid oor hierdie sake 'n stimulus en korrektief kan wees waar sake nie na behore verloop nie. Hulle steun die beginsel van voortdurende studie en aandag aan gevalle op hulle weg na onafhanklikheid en selfregering. Hierby sluit ook nóu aan ekonomiese en sosiale ontwikkeling. Die harde werklikheid het die C.C.I.A. al gedwing om ook te sê: Hierdie proses van dekolonisasie op sigself los die saak nie op nie, maar hiermee saam hang die ekonomiese en politieke bestaansmoontlikheid, wat daardie lande moet bied wat al ver op hierdie pas gevorder het. Hulle is bekommerd oor die swak plekke wat in die vinnige evolusie en ontwikkeling van die laaste tyd blyk in die ekonomiese, sosiale, opvoedkundige en politieke strukture van hierdie volke. Daarom moet daar vinniger gewerk word aan die „fondamente" van blywende en vrye politieke strukture.

Daarom is al verklaar: Die C.C.I.A. verheug hom in die onafhanklik-wording van baie volkere die laaste tyd. Maar hulle sien daar is nog volke wat onder vreemde politieke dominasie staan. So-iets is onregverdig en die Christelike gewete veroordeel dit.

In die belang van menslike reg en vrede moet die politieke mag aan sulke mense oorgedra word. Dit mag wees dat party nog nie voorbereid is om die verantwoordelikhede van politieke onafhanklikheid op hulle te neem nie. "In such cases the process of necessary preparation must be greatly accelerated". As daar mindarhede is, moet hulle regte gewaarborg word deur die volk wat onafhanklikheid bereik. (Omtrent soos Dingaan se waarborg aan Piet Retief). Die minderhede mag geen regte behou om die meerderheid se regte en die welvaart van almal te veto nie.

1. Trustgebiede. Hulle hou hulle met die laaste 3 trustgebiede besig nl. Nu-Guinee, Mauru (eiland in die Stille Oseaan) en 'n gebied van Suidsee-eilande onder administrasie van die V.S.A. Daar word aan almal se onafhanklikheid gewerk. So het hulle Australië beveel om die fosfaat-industrie te Mauru oor te gee aan die 5,600 inboorlinge, asook hul politieke onafhanklikheid nie later as Jan. 1968 nie.

2. Die Spesiale Komitee van 24. Hierdie komitee beliggaam die sterk anti-koloniale stem van die V.V.O., dit "helps to increase the pressures for prompt emancipation. It is the most active of U.N. bodies." Hulle het 'n "Declaration on the Granting of Independence to Colonial Countries and Peoples" uitgereik, waarin die euwels van vreemde oorheersing gemeld word en die bekende snare getokkel word dat elke volk die reg het om self oor hom te beslis. Alle state word opgeroep om hierdie Deklarasie te eerbiedig. "Frustrations of the majority over somber developments 
in southern Africa are reflected in strongly- worded resolutions, which may have little immediate relationship to the power factors reuired to give them effect or to the human rights involved."

\section{Ekonomiese en Sosiale Ontwikkeling.}

Deur die afgelope jare heen het die C.C.I.A. veel in hierdie opsig gedoen, met die klem op hulp en nogeens hulp in al sy vorms, maar veral so dat die ekonomie van die ontwikkelende lande moes bloei deur handel en doodgewone hulpaanbiedings in welke vorm ookal want, so het die W.R. in Nu-Delhi 1961 gesê: "The new nations and their existing political order depend on their success in achieving rapid economic progress to match the expectations of their peoples".

In hierdie opsig is die stigtings van die volgende verwelkom nl. "Division of inter-Church aid and its specialized Assistance to Social Projects," die "Dept. of Church and Society," en die "Pontifical Commission on Justice and Peace".

Om die planne vir sodanige ontwikkeling as waarvan hier sprake is uit te werk, is 'n strategie amptelik te Bangalore in 1961 al uitgewerk. Die elf punte daarvan is onder belanghebbendes van die V.V.O. gesirkuleer. Dit beoog veral 'n meer gekoördineerde hulpskema. So 'n koördinasie, sê hulle, is uiteraard net deur die V.V.O. en sy betrokke liggame te bewerkstellig.

Hier skyn toe ' $n$ kleur van pessimism deur. Dit gaan nie so vlot as wat hulle graag sou wou sien nie. Nasies wat aan hulpprogramme meedoen is gladnie gretig om hulle programme aan die nuuskierige oë van die krappende en soekende ondersoek van 'n V.V.O. komitee te onderwerp nie. Selfs die ontwikkelende lande toon ' $n$ terughoudendheid om hulle vordering wêreldkundig te maak. Dit lyk of die lede (nog nie) gereed is om hulle internasionale liggaam allerhande vryhede toe te laat behalwe op indirekte wyse nie. Dit bly dan ' $n$ bron van bekommernis vir die C.C.I.A.

Op hierdie terrein waarop die soeklig nou val, moet gepraat word oor die voedselkrisis wat in baie wêrelddele dreig, soos verslae oor ondervoeding en swak produksie ook toon. Dit het direk met die sosiale aspekte van ontwikkeling te doen. ' $n$ Vinnige sosiale struktuurverandering, sonder behoorlike behuising in ' $n$ snel verstedelikende bevolking, gee net chaos af. Nou is dit ook hierdie lande wat ' $n$ bevolkingsontploffing beleef. Dit spreek vanself as die mense ewe skielik politiek vry word, hulleself regeer, oordonder word met die geskenke van 'n moderne tegnologiese samelewing wat hulle nie self voortgebring het nie maar hulle eerder verwar, 
dat Christene se oë behoort oop te gaan vir die on-menslike wat in hierdie gedwonge rypwordingsproses en onrealisties snelle ontwikkelingspogings geleë is, nog meer as waarop die Bangalore strategie boog.

In elk geval het die bevolkingsaanwas hulle sover gaande gemaak dat hulle beplande ouerskap wyd en syd probeer verkondig, en hulle span ook kerke en mediese voorligting in diè verband in. Dit alles is dan ' $n$ poging om balans te kry tussen die bevolking en die voedselproduksie, sonder dat daar 'n tragedie later sal plaas. vind.

Maar intussen word die klem steeds op tegniese en finansiële hulp gelê. Die W.R. het in $19581 \%$ van die nasionale inkomste aanbeveel vir dergelike hulpverlening, maar dit is nie wêreldwyd verkry nie sodat $1 \%$ van die bruto nasionale produksie voorgestel word, wat $20 \%$ meer as die een persent van nasionale inkomste behoort te wees ( 15 biljoen dollar).

Met die tegniese en finansiële hulp hang die saak van opleiding nou saam. Die ekumeniese verantwoordelikheid in hierdie verband word weerspieël deur die wêreldwye opvoedkundige werk wat oor baie jare heen deur Christelike sending- en verwante liggame gedoen is. Die C.C.I.A. het kontak bewerkstellig tussen deskundiges van kerkskole en Unesco, veral met die oog op sake in Afrika. Massa-publikasie verspreiding is vir 'n 3 jaar tydperk beoog om ongeletterdheid te bekamp.

Op die terrein handel en nywerheid het die C.C.I.A. steeds riglyne neergelê en raad probeer gee in verband met algemene handelsake, prysvariasies, verbruikersgoedere, voorkeurtariewe, internasionale ooreenkomste ens. Hulle meld egter "Unfortunately, the major trading nations are still primarily concerned about improving the conditions of trade among themselves."

\section{E. Vlugtelinge en immigrasie.}

Vir hierdie saak het die V.V.O. 'n hoë-kommissaris aangewys. Baie werk word in hierdie verband gedoen, maar die Arabiese probleem in Palestina baar sorg. I.v.m. immigrasie het die C.C.I.A. konsult-status by die "Inter-governmental Committee for European Migration".

\section{F. Die Ontwikkeling van Internasionale Instellings.}

Uiteraad is die belangrikste liggaam vir die C.C.I.A. die V.V.O. Met die totstandkoming van die V.V.O., so word verklaar, het die kerke 'n stem daarby gehad. Ondersteuning vir hierdie liggaam was 
steeds 'n belangrike punt in die ekumeniese getuienis van die kerke voor die wêreld met sy nasies. Tog het die noodsaak van sterk internasionale liggame in die huidige atoom-en ruimte-wêreld duidelik geblyk. Hier dien die V.V.O. sy doel; dit moet groei en deur die Christendom gebruik word.

Die rapport konkludeer met aanwysinge van baie studiewerk wat voortdurend gedoen word in die internasionale veld, en met gebruikmaking van die dokumentasie wat die V.V.O. en sy liggame bied. Hulle benodig voortdurend agtergrond-materiaal vir optrede en besluite. Sommige word opgeteken in die "C.C.I.A. Briefs". (Agtergrond Inligting).

Terwille van volledigheid word baie kortliks teruggegryp na dinge wat ou nuus kan wees, ten einde die volle motivering ook vir verklarings van die liggaam te hê, en ook huidige gebeurtenisse in die regte perspektief te kry. Ons beperk ons tot die vier jongste "C.C.I.A. Briefs".

A. No. 14, Mei 1965, Vietnam.

Wat hierdie land betref word 'n oorsig oor die geskiedenis daarvan gegee van die afgelope $2000 \mathrm{jr}$. ten einde die nodige agtergrond vir beoordeling te hê.

Elke godsdiens se invloed word genoem - vanaf die Mahajana Boeddhisme, Confucanisme, Taoisme tot by die Roomse invloed van die Jesuiete van vorige eeue en dan uiteindelik die Franse. Tydens die Diem-bewind van die laaste jare het lg. invloed sterk toegeneem.

Die invloed van die Westerse kultuur op hulle gewoontes en lewenswyse het meer net die Suide geraak, daar die Noorde te konserwatief was.

In die tyd van die Franse oorheersing het daar vyandskap begin opbou, veral van die kant van die Cao Dai en Hao-Hao sektes, wat die voorlopers was van die vyandelike leërs van vandag. Dit is aangevul deur die Franse politiek van assimilasie van die bevolking in die Franse kultuur, en daar is by staatsaanstellings veral op hierdie soort van dinge gelet.

Die tydperk van Westerse ondergang het met die $2 \mathrm{e}$ Wêreldoorlog begin. In daardie tyd beleef hulle die opkoms van Ho Chi Minh, stigter van die Indo-Chinese Kommunistiese Party, wat in Vietnam die Nasionale Rewolusionêre Beweging begin het $\mathrm{nl}$. die Viet-Minh. 
Na die val van Japan het die V.S.A. sy verskyning gemaak, en dadelik teëstand van die Viet Minh ondervind. Nietemin het Frankryk en die V.S.A. daar gebly - eg. tot die val van Dien Bien Phu. In 1954 was daar pogings tot oplossing van die kwessie, in Geneve. Tot die staakvuurooreenkoms met Frankryk nou kom, geteken deur die Franse en die Viet-Minh, het hulle die volgende vergelyk getref :-

(a) Hulle maak 2 sones, ongeveer ewe groot, een onder die VietMinh en die ander onder die Frans ondersteunde regering wat toe al daar was.

(b) Onder supervisie van Indië, Kanada en Pole moet in beide verkiesings gehou word om 'n verenigde regering daar te stel.

Tydens die konferensie al distansieer Vietnam deur sy minister van Buitelandse Sake hom van 'n verdeling van die land. Die saak is toe verder in die Suide opgeneem, wat interne moeilikhede ten gevolg had. Uiteindelik val die Diem-regering deur 'n militêre staatsgreep.

Verkiesing is toe nooit gehou nie. Die V.S.A. het ekonomiese hulp aan die Suide gebied. Daar kom egter die Viet-kong tot stand wat guerilla-kryg voer. Die V.S.A. moes sy militêre hulp vermeerder. Wat as opstand teen Europese dominasie begin het, word naderhand 'n stryd tussen verskillende groepe om beheer van die bevryde land.

Die Kommissie verklaar dat hierdie kwessie woordelik besleg moet word, en nie met die swaard nie. Die C.C.I.A. het in 1965 die volgende verklaring uitgereik (Verkort).

1. Die leiers van die C.C.I.A. maan tot versigtigheid in die komplekse situasie t.o.v. Vietnam. Nadat hulle in aanraking met komiteelede van die East Asia Christian Conference en die National Council of Churches of Christ in the V.S.A. was, het hulle 'n Interim Rapport oor SuidViëtnam uitgereik. In hierdie verklaring wil hulle nog duideliker spreek sonder om 'n oordeel te vel - slegs om die diepe besorgheid van miljoene Christene in die W.R. uit te spreek; om hulle met die tragiese lot van die Vietnamese bevolking te identifiseer en om sekere optrede aan te beveel.

2. Hulle verklaar die futiliteit van verdere militêre optrede, hoewel dit met die huidige toestand so is dat stryd makliker ontbrand en mens kan aanvaar dat 'n kritiese wêreldopinie in Asië sal sterker word. 
3. Hulle verklaar dat geregtigheid beter gedien kan word op 'n vredevolle wyse, en deur pogings om die vrede te bewaar. 'n Beroep moet op die betrokkenes gemaak word om hulle agressie te staak. Dit is noodsaaklik, anders sal geen verdere samesprekings vorder nie.

4. 'n Vredeskonferensie is moontlik - en eerbaar - maar net "if face-saving is abandoned, and there appears a readiness to take necessary risks without guarantees of success in advance" (bls. 7).

5. Terwyl baie voorstelle oor samesprekings al gemaak is, en na moontlike bemiddelaars gesoek is, voel hulle dat die lande wat die vertroue van die betrokke partye mag geniet die geskikste sal wees bv. Rusland. Engeland of Frankryk - maar nog beter, die lande wat digby lê en groot belang by 'n oplossing sal hê.

6. Hulle sien die beste oplossing as daardie een wat deur die bevolking van Suid-Vietnam self as die beste geag word. Dit vereis wel vrye uitdrukking van hulle begeerte.

7. Daar is nie uit die oog te verloor die magteloosheid van die V.V.O. om iets aan die saak te doen nie - hoofsaaklik, reken hulle, a.g.v. die afwesigheid van Rooi Sjina in die organisasie.

8. "Christians as well as all men of goodwill can find their obligation and opportunity in the struggle to convert evil into good and to make what is potentially destructive rebound to the benefit of mankind".

So eindig die oproep.

\section{OPMERKING.}

T.o.v. Vietnam word nêrens positief gewys op die gevaar van die toenemende, infiltrerende kommunisme nie. Geen rekening word gehou met die harde werklikheid van die kommunistiese leerstellings en hulle rewolusionêre agressie nie. Dààr word vrede geroep en militante optrede afwys, maar nie i.v.m. terroristebedrywighede in Afrika nie. Dan: Waarom word die beslegting verwys na buurvolke wat beslis nie as Christelik bestempel kan word nie?

\section{B. No. 15, Okt. '65, S.W.A.}

Terwyl die saak oor S.W.A. in die Wêreldhof te Den Haag nog sub judice vas, het hierdie kerklike kommissie dit goedgedink om 'n agtergrondskets van die saak te gee en ook, in afwagting 
op die uitspraak, positiewe stappe aan die hand te doen teen die onchristelike onderdrukking wat apartheid meebring.

Omdat die agtergrond by ons bekend is, handel ons dit kursories af.

1. Na 'n uiteensetting oor die ligging en geaardheid van S.W.A., word syfers genoem i.v.m. die landbou en visserye, en veral mynbou en minerale, waarvan diamante die vernaamste is.

2. Dan geniet die bevolkingsyfers van die onderskeie volksgroepe die aandag, wat dan die resultaat lewer dat die blanke bevolking slegs $14 \%$ van die totaal verteenwoordig.

3. Die vroeëre geskiedenis van Suidwes toon veral die uitstaande kenmerke van die uiters onderdrukkende oorheersing van die Duitse regime, en dit na bittere vyandelikhede onder die toenmalige inheemse volksgroepe. Die Duitse beheer is met die kapitulasie aan die S.A. magte in Jun. 1915 beëindig.

4. Toe is die internasionale status van S.W.A. deur die Volkebond in 1920 bepaal. Die gebied sou geadministreer word deur die regering van die Unie van S.A. onder 'n C.-mandaat; juis met die doel dat die gebied nie weer sulke behandeling sou ontvang as wat onder Duitsland die geval was nie. 'n C.-mandaat beteken dat so 'n gebied ' $n$ " integral portion of the territory of the mandatory power, subject to safeguards in the interest of the indigenous population" sou wees en S.A. sou sy wette daar kon laat geld en alleen die allerbeste doen om die inwoners se welvaart te verseker. Maar, sê die kerklike komitee, in daardie dae was die woord apartheid onbekend.

5. Nou word die toenemende klagte oor die S.A. praktyke in Suidwes genoem, en die pogings van die V.V.O. om verslae van S.A. af te dwing, asook die weiering van S.A. om verslag te gee aan 'n liggaam wat niks te doen het met die toekenning van die mandaat nie.

6. Daarna volk die pogings wat uiteindelik uit geloop het op die besoek van Carpio en Martinez aan Suidwes, totdat Ethiopië en Liberië die hofsaak aanhangig gemaak het.

7. Die Odendaalverslag van 1964 vir S.W.A. word genoem onder die hoof "South Africa's Response". Dit meld dio 
5 jaar ontwikkelingsplan van ' $n$ aanvanklike R156 miljoen rand en ' $n$ volgende van R90 miljoen.

8. Die agtergrondkommentaar konkludeer dat, solank uitspraak in die hofsaak nog nie gegee is nie, dit nie vooruitgeloop kan word nie. Nietemin word nuwe probleme verwag t.o.v. die hele suidelike Afrika. Die uitvoerende komitee van die C.C.I.A. het ook in Julie 1965 die volgende verklaring uitgereik; wat saamgevat lui :-

(a) Hulle beskou met sorg die verslagtende situasie in die lande in Suider-Afrika waar die beginsel van wit minderheidsregering die basis is van die onderdrukkende optrede en hulle betreur die verset van S.A., Rhodesië, Angola en Mosambiek.

(b) Hulle wys op die sukses van die politieke selfstandigheid van Basutoland, Bechuanaland en Swaziland.

(c) Hulle bevestig hulle voorneme om rassediskriminasie te veroordeel, maar kontak moet behou word met kerke, organisasies en indiwidue om elke moontlikheid van versoening te benut. Besoeke en veral uitruilings van studente en opvoedkundiges word sterk aanbeveel.

(d) Hulle wil moeite doen om die implikasies van immigrasie t.o.v. die Suid-Afrikaanse ekonomie en die daarbybehorende maat van verantwoordelikheid op die skouers van die verarmde en geregimenteerde nie-blanke arbeidsmag onder die aandag van voornemende immigrante te bring.

(e) T.o.v. Rhodesië sal die Verenigde Koninkryk steeds gevra word om ' $n$ aanvaarbare konstitusie aan te bring wat aanvaarbaar vir almal kan wees.

(f) Waar kerke finansieël sal ly deur rassediskriminasie of wetgewing, behoort die hele Christelike gemeenskap in die wêreld hulle by te staan.

(g) Hulle plaas 'n groot vraagteken agter die sg. naiewe opvatting in blanke S.A. dat agter die sg. bevryding van die wit heerskappy daar kommunistiese magte skuil. Hierdie vryheidsideaal by die inboorlinge is eerder ' $n$ historiese ontwikkeling en moet erken word as ' $n$ strewe na ' $n$ waardige plek in die mensdom.

(h) Om die wit minderhede gerus te stel moet Afrikaleiers beweeg word om onderlinge twiste by te lê, 
want dit word gebruik om hulle onverantwoordelikheid uit te wys en dien slegs daartoe dat hulle as politiek onvolwasse gesien word.

"The C.C.I.A. . . . recognizes both the growing impatience of African opinion and also the uncertainty and fear among the white people in Southern Africa." Hulle sal volhard in hulle strewe en sien in S.A. die land wat later - as alles eers hier reg is, leiding aan die hele Afrika sal gee.

\section{No. 16, Mei 1967.}

'n Kort agtergrondskets oor 'n geen-besoedelingsooreenkoms wat i.v.m. kernbomme aangegaan behoort te word. Skynbaar is die konsep van so 'n ooreenkoms in wording maar niks is nog voor die agtien lande komitee geplaas nie. Drie punte is darem al duidelik:

(a) Kernmoondhede sal nie hul kennis of wapens versprei sodat ander lande dit ook bekom nie.

(b) Die res van die lande sal onderneem om dit nie te probeer verkry of ontwikkel nie.

(c) 'n Sisteem van internasionale inspeksie sal aanvaar moet word om hierdie reëls te handhaaf.

Dit spreek vanself dat hierteen teëkanting is, maar sonder enige formele uitspraak is die C.C.I.A. van mening dat die geleentheid om 'n ooreenkoms te bereik, nie onbenut gelaat moet word nie. Dit lê op die weg na ontwapening.

D. No. 17, Des. 1967, Unctad New Delhi 1968.

Unctad beteken in Engels: United Nations Conference on Trade, Aid and Development. ' $n$ Eerste vergadering is in 1964 in Geneve gehou, saamgeroep deur die onder-ontwikkelde lande. Die doel was om die kloof tussen arm en ryk volke te oorbrug d.m.v. hulp aan hierdie lande wat ontwikkelende lande genoem word, en die herorganisasie van die wêreldhandel. Uiteraard het hierdie eerste vergadering nie veel vrugte afgewerp nie, omdat die welvarende lande gevoel het dat die onmoontlike van hulle gevra word terwyl die ander gefrustreerd gevoel het omdat die sake nie vinnig genoeg na hulle sin gevorder het nie. Daar was 77 verteenwoordig as onder-ontwikkelde lande, en vir die 1968 vergadering word 100 verwag.

Vir hierdie jongste vergadering word nou die probleme ge- 
stel $\mathrm{nl}$. hoe om die arm lande se handel te bevorder, aan hulle voorkeur tariewe te bied, die ryk lande se markte vir hulle uitvoere oop te stel ens. Die C.C.I.A. sê dat eiebelang en spesiale voordele moet wyk voor die algemene vooruitgang, en dat Christene hier ' $n$ besondere taak het.

Hierdie arm 77 lande het in Algiers byeenkom in 1967 (Okt.) en aanbevelings opgestel vir die komende vergadering. Naas prysbepalings en voorkeure in hulle guns val die klem op hulp (aid) op verskillende maniere.

Die weerklank van hierdie hulpaanbiedinge kom toe spoedig by ' $n$ vergadering in Nov. 1967 te Geneve waar verteenwoordigers van Protestantse Kerke uit Engeland, Duitsland en Frankryk met Roomse adviseurs en leke-deskundiges beraadslaag het oor hulle onderskeie regerings se beleide by die volgende 1968 vergadering. Een woord kan gebruik word vir hulle aanbevelings en dit is hulpaanbiedinge, en op so 'n wyse dat die onder-ontwikkelde lande tog nie gebind sal word aan die wat hulp gee nie.

Die C.C.I.A. het in Julie 1965 'n verklaring uitgereik waarin die noodsaak beklemtoon word dat aan die handel in al sy fasette besondere aandag gegee sal moet word, omdat dit die belangrikste middel is om die lande te laat ontwikkel. Dit het groot voordeel vir die politieke verhoudings tussen ryk en arm nasies.

Dit wat betref die vier laaste sirkulêres oor die genoemde sake. Dit is duidelik dat die C.C.I.A. op die spoor van die algemene tendens vandag begeester is met ' $n$ proses van uitwissing van grense, veral op sosiale en ekonomiese vlak, sonder inagneming van die werklike bevordering van die sg. onderontwikkeldes en verdrukte meerderhede se eintlike opvoeding, en behoud van sy eiewaarde om as selfstandige en selfrespekterende mens sy heil uit te werk en langs die gesonde weg van eie inisiatief die blywende vir hom op te rig nie. 